\title{
WestVirginiaUniversity
}

THE RESEARCH REPOSITORY @ WVU

Graduate Theses, Dissertations, and Problem Reports

2006

\section{The development of a typology for interracial relationships}

Juan M. D'Brot

West Virginia University

Follow this and additional works at: https://researchrepository.wvu.edu/etd

\section{Recommended Citation}

D'Brot, Juan M., "The development of a typology for interracial relationships" (2006). Graduate Theses, Dissertations, and Problem Reports. 861.

https://researchrepository.wvu.edu/etd/861

This Thesis is protected by copyright and/or related rights. It has been brought to you by the The Research Repository @ WVU with permission from the rights-holder(s). You are free to use this Thesis in any way that is permitted by the copyright and related rights legislation that applies to your use. For other uses you must obtain permission from the rights-holder(s) directly, unless additional rights are indicated by a Creative Commons license in the record and/ or on the work itself. This Thesis has been accepted for inclusion in WVU Graduate Theses, Dissertations, and Problem Reports collection by an authorized administrator of The Research Repository @ WVU. For more information, please contact researchrepository@mail.wvu.edu. 
The Development of a Typology for Interracial Relationships

Juan M. D’Brot

\begin{abstract}
Thesis submitted to the Eberly College of Arts and Sciences

At West Virginia University

In partial fulfillment of the requirements for the degree of
\end{abstract}

\author{
Master of Arts \\ in \\ Communication Theory and Research
}

Theodore A. Avtgis, Ph. D., Chair

Keith Weber, Ed. D.

Scott A. Myers, Ph. D.

Department of Communication Studies

Morgantown, West Virginia

2006

Keywords: Interracial Relationships, Relationship Development, Focus Group Methodology, Typology Development 


\section{Abstract \\ The Development of a Typology for Interracial Relationships \\ Juan M. D’Brot}

The purpose of this study was to determine whether Foeman and Nance's (1999) model of interracial relationship development could be adapted into a generalizable interracial relationship typology and whether there would be distinct differences in the affective, cognitive, and behavioral dimensions of each stage. Long-table analysis of four focus group interviews confirmed differences among the four stages of Foeman and Nance's model. Further examination of focus group transcripts revealed differences between the affective, cognitive, and behavioral dimension of each stage, but few differences between the affective and cognitive dimensions across stages. Implications for the study of relationship development, limitations, and directions for future research are discussed. 


\section{ACKNOWLEDGEMENTS}

I would like to thank those people who have contributed their time, energy, and encouragement to the completion of this document and this year.

To Ted: Thank you for your guidance, ability to deal with my wordiness and overwriting, your incessant patience, and the pitchers you provided. Hope the piano holds up. This has been an experience I will never forget and one that I owe you for.

To Keith and Scott: Your insights, comments, concerns, and guidance were invaluable. I appreciate everything you both provided.

To My Wife: For putting up with long nights, reading and rereading my rough drafts (thanks for being an English teacher), and generally loving me throughout my many moods during work.

To My Friends and Family: Thank you for the words of encouragement and pats on the back. Holler at your boy. 


\section{TABLE OF CONTENTS}

Page

$\begin{array}{lll}\text { ABSTRACT } & \text { ii }\end{array}$

ACKNOWLEDGMENTS $\quad$ iii

$\begin{array}{ll}\text { INTRODUCTION } & 1\end{array}$

CHAPTER

I. REVIEW OF LITERATURE 3

$\begin{array}{ll}\text { Model of Interracial Relationships } & 6\end{array}$

$\begin{array}{ll}\text { Racial Awareness } & 7\end{array}$

Coping with Social Definitions of Race 9

Identity Emergence $\quad 11$

$\begin{array}{ll}\text { Maintenance } & 12\end{array}$

Extension of Interracial Relationship Model 15

$\begin{array}{ll}\text { II. METHOD } & 17\end{array}$

Focus Group Methodology 17

$\begin{array}{lr}\text { Participants and Procedures } & 18\end{array}$

$\begin{array}{ll}\text { Analysis of Data } & 19\end{array}$

III. RESULTS 21

$\begin{array}{ll}\text { Research Question One } & 21\end{array}$

$\begin{array}{ll}\text { Research Question Two } & 26\end{array}$

$\begin{array}{lr}\text { IV. DISCUSSION } & 29\end{array}$

$\begin{array}{ll}\text { Limitations } & 36\end{array}$ 
TABLE OF CONTENTS (Continued)

$\begin{array}{ll}\text { Future Directions } & 37\end{array}$

$\begin{array}{ll}\text { References } & 39\end{array}$

APPENDIXES

A. Script for Focus Groups 44

B. Typology of Interracial Relationship Development 47

C. Affective, Cognitive, and Behavioral Dimensions of Each Stage 51

D. Curriculum Vitae 55 


\section{Introduction}

The number of interracial marriages has dramatically increased in the United States since the abolition of laws prohibiting such unions. The large-scale immigration in recent decades, especially from Latin America and Asian countries, has contributed to the increase in the population of mixed race couples in the United States (Results of the 1996 Race and Ethnic Targeted Test, 2001). According to the U.S. Census Bureau (1999), of the 40,491,000 married couples in the United States in 1960, 149,000 were interracial (0.3\%). As of 1998, of the 55,305,000 married couples in the United States, 1,348,000 were interracial (2.4\%). According to the U.S. Census Bureau (1998), only $21.2 \%$ of the interracial marriages in the United States were between Black and White individuals. Of all interracial marriages, $24.6 \%$ were American Indian and White couples, $18.1 \%$ were Asian and Pacific Islander couples, and $35.9 \%$ were other race (i.e., Hispanic and any other race not identified as Black, White, Asian and Pacific Islander, American Indian, Eskimo, or Aleut) and White couples (U.S. Census Bureau). These numbers, however, may not provide an accurate illustration of all interracial relationships. That is, couples not containing a White partner and non-married couples are not part of these statistics.

According to the 2000 U.S. Census, a large number of people in the United States are non-White. Although a significant portion of minorities were Black (i.e., 12.3\%), other racial groups must also be considered. Hispanics accounted for $12.5 \%$ of the population, Asians accounted for $3.6 \%$ of the population, and people of other races (i.e., all people not included in the White, Black, American Indian, Eskimo, Aleut, Asian or Pacific Islander race categories) accounted for $2.4 \%$ of the population. The significant number of non-White people in the United States, coupled with an increase in non-White immigration adds to an increased probability of people participating in interracial relationships. 
In addition to the proliferation of interracial marriages, the number of interracial children has increased from 500,000 in 1970 to approximately two million in 1990 (results of the 1996 Race and Ethnic Targeted Test). Due to the increase in the number of interracial children and the number of people who are in committed interracial relationships but not married, there is a need for researchers to focus on unmarried individuals in interracial relationships. The continued increase of immigration and interracial children warrants further study in regards to the interaction and communication between interracial couples. 


\section{CHAPTER ONE}

Review of Literature

With such a high percentage of the United States population being non-White, an inclusive typology examining the development and functioning of interracial relationships should be created. Researchers have examined the communication patterns of the Caucasian-American college sophomore extensively (see DeWine \& Daniels, 1992), but have overlooked communication patterns between other ethnicities. Scholars have studied other variables such as willingness to date interracially and characteristics of those who have dated interracially (DeWine \& Daniels; Kaplan, 2002). Kaplan examined the motivations and willingness of White college students to date interracially. He found that external factors (i.e., physical attractiveness, approval, personality) were the main determinants of dating interracially. Although White men's involvement in interracial relationships was determined by external factors, White men generally preferred other White partners to all other minorities. Yancey (2002) found several characteristics prevalent in White people, which determined participation in interracial relationships. These exhibitors included being male, Catholic, younger, politically liberal, attending an interracial school, and living in an integrated community. It is important to note that these characteristics were not a profile but independent factors, which increased participation in interracial relationships. Even in light of previous research examining increased motivations and characteristics of interracial relationships, research has yet to address other factors such as relational development unique to interracial couples. The interracial couple may face differences in uncertainty stemming from individual differences, societal pressures, status differentials, and cultural origins that may not be experienced by same-race couples (Hall, 1976; Kaplan, 2002; 
Yancey, 2002). Thus, research should focus on the influence of these unique features on relational development specific to interracial couples.

Because individual cultures are different from one another, people with backgrounds rooted in different cultures interacting may experience unique challenges, especially during relational development. Not only do relational guidelines differ between cultures, but status differentials between races and cultures could further complicate interactions (Hofstede, 1984). There may be socially inherent differences between races in terms of status that could play a role in how couples communicate. For example, people from more masculine cultures "expect men to be assertive, ambitious, and competitive... [and] expect women to serve and to care for the nonmaterial quality of life, for children and for the weak" (p. 390, Hofstede, 1984). Additionally, differences between cultures (e.g., power distance or uncertainty avoidance) can lead to inconsistencies in the amount of information each member of an interracial relationship either discloses or desires to receive (Hofstede). Not only could status differentials affect how couples interact with each other, but differences in status could impact how couples interact with others. Because of the assumption that there are inherent differences associated with racial status (i.e., majority/minority) (Kaplan, 2002), individuals in interracial relationships may experience more strain and ostracism than their intraracial counterparts. These majority/minority differences may stem from a powerlessness and lack of self-affirmation resulting from historical group or culture power differences (Hall, 1976). Foeman and Nance's (1999) examination of groups through the lens of Harding's (1991) Standpoint Theory further support this explanation. Standpoint Theory "contends that the social groups to which we belong guide how we experience the world, ourselves, and relationships with others" (Houston \& Wood, 1996, p.41). The social standpoints of differing groups are shaped by cultural practices based on characteristics such as race, which 
serve to create unequal status and opportunity (Houston \& Wood). Interracial relationships may be different from same-race relationships because of the strain or ostracism people in interracial relationships may experience as a result of group membership and cultural differences (Hall, 1976; Hofstede, 1984; Houston \& Wood, 1996; Kaplan, 2002; Yancey, 2002).

However, even when examining interracial relationships, researchers have primarily examined Black and White couple interactions (Baldwin, 2000; Martin, Hecht, \& Larkey, 1994; Mills, Daly, Longmore, \& Kilbride, 1995; Watts \& Henriksen, 1998; Yancey, 1998). Harris and Kalbfleisch (2000) examined how race influences the communicative process during interracial (i.e., Black and White) interactions. The researchers determined participants were resistant to the idea of dating interracially. Harris and Kalbfleisch also determined society and family were the primary deterrents of people becoming involved with interracial partners. However, people who became involved in interracial relationships enacted social distancing strategies more than individuals in same-race relationships. The social distancing strategies used to exhibit interest by people involved in interracial relationships included waiting to be asked out, waiting to be flattered, waiting for the other person to be interested in them, hiding interest in the other person, discussing mutual interests and events, and flirting about attraction but avoiding date initiation. People in same-race relationships used more social approach strategies. The social approach strategies used to exhibit interest by same-race couples were directly asking another on a date, identifying another's relationship status, calling another on the phone, and openly stating attraction towards another.

Martin, Hecht, and Larkey (1994) examined the interethnic conversations and the proposed conversational improvement strategies between Black and White individuals. The conversational strategies examined were asserting a point of view, open-mindedness, avoidance 
of unpleasant topics, identifying a lack of improving a dissatisfying conversation, giving in to another's demand, interaction management, and other orientation (i.e., increasing the involvement of the other person in the conversation). The researchers identified a stronger relationship between conversational improvement strategies and communication issues (i.e., powerlessness, stereotyping, authenticity of interaction, expressiveness, goal attainment, acceptance, and understanding) for Black people than for White people. Black individuals also emphasized joint actions in their conversational improvement strategies whereas White individuals emphasized strategies involving actions of the other interactants. Mills, Daly, Longmore, and Kilbride (1995) examined undergraduate students' perceptions of family acceptance regarding interracial (i.e., Black and White) relationships. The researchers found, despite Black people perceiving interracial relationships more positively than White people, overall, men and women perceived interracial relationships negatively. The findings also indicated that women were less accepting of interracial friendships than men and family perceptions of interracial relationships would be negative, regardless of the perception of the people involved in the interracial relationship.

It is clear from the review of literature that research efforts have primarily examined the White/Black relationship (Baldwin, 2000; Martin, et al., 1994; Mills et al., 1995; Watts \& Henriksen, 1998; Yancey, 1998). The research on interracial relationships, other than Black and White couples, is not necessarily representative of the relational activity of other non-Whites. Yancey (2002) determined a significant number of other minorities have dated interracially. In addition to the $35.7 \%$ of Whites and $56.5 \%$ of Blacks who have dated interracially, over half of Hispanics (55.4\%) and Asians (57.1\%) have dated interracially. The significant number of nonWhites interracially dating coupled with the increase of immigration and the increase of mixed- 
race children exemplifies the need for an inclusive theoretical understanding of interracial relationship development.

\section{Stages of Interracial Relationship Development}

Foeman and Nance (1999) developed a model of interracial relationship development specific to Black and White interracial couples. To develop this model of relational development, the researchers conceptualized the strategies of successful interracial relationships and suggested four stages of interracial relational development stemming from previous theoretical and empirical investigations. The stages identified were (a) racial awareness, (b) coping with social definitions of race, (c) identity emergence, and (d) maintenance. Because these stages were based on issues unique to Black and White couples (see Foeman \& Nance, 2002), these stages may be present in other interracial relationships given the stressors on interracial relationships discussed earlier. A Black and White couple confronts issues relevant to differences in culture, majority/minority issues, and social status differences. Regardless of origin or geographic location, a non-White individual in a relationship with a White individual should face the same issues that a Black or White individual in an interracial relationship would. It is important to note that although differences within interracial couples involving members of various races probably exist, there could be consistent differences between same-race and interracial couples. Therefore, the stages involving the development of Black/White interracial relationships may be relevant to the development of any interracial relationship.

\section{Racial Awareness}

According to Greene, Watkins, McNutt, and Lopez (1998), racial awareness refers to the level of awareness of how race, ethnicity, culture, language, and related power status operate in life while simultaneously understanding the dynamics of racism, oppression, and discrimination. 
In addition, Vonk (2001) noted how transracial adoptive parents needed to be aware of their motivation for adopting an extraracial child and needed to become sensitized to racism and discrimination. These claims logically follow Foeman and Nance's (1999) stage of racial awareness.

According to Foeman and Nance (1999), an interracial couple's first stage of racial awareness is both an interpersonal and cultural experience marked by awareness of attraction towards the other individual and sensitization of the racial place of the other individual. Becoming sensitive to another's racial place involves understanding each other's group membership, becoming aware of their social roles in relation to their group, and developing a common perspective in the role race plays in relationships (Foeman \& Nance). Foeman and Nance noted how same-group couples differ from Black and White couples in learning patterns and recognizing intentions. This is attributed to the fact that same-group couples belong to a homogenous group and are familiar with that group's norms. The same dissimilarity in regards to group membership has been observed in other non-White groups (e.g., Hispanic, Asian, Eskimo, etc.) (Hofstede, 1984). The members of interracial couples should become aware of four perspectives: the individual's own, his/her partner's, his/her collective racial group's, and his/her partner's racial group (Foeman \& Nance). Couples in this stage should also recognize how race plays a role influencing the development of the relationship. During racial awareness, the members of an interracial couple acknowledge his/her attraction towards a member of a differing racial group and how that attraction will be scrutinized socially. The volatility of such attraction may not be limited to that of White and Black couples, but could be present among any couple of differing races. Racial awareness is also created through people sensitizing themselves to their partner's racial place and status in society. Foeman and Nance discussed how cultural privileges 
differed between White and Black partners during everyday interactions and how both members of the relationship "develop sensitivity to a sometimes uncomfortable alternative perspective" (Foeman \& Nance, 1999, p. 550). The development of racial sensitivity is an important prerequisite for the development of a racial consciousness necessary to sustain interracial relationships. Racial sensitivity, however, may very well be present in interracial relationships beyond those involving Black and White couples. Although different combinations of interracial couples will become sensitive and aware of their respective perspectives, members of any interracial couple should become racially aware of one another through racial sensitivity. Coping with Social Definitions of Race

According to Foeman and Nance (1999), once interracial couples have established racial awareness, the couple should begin to cope with social definitions of race. Because so many definitions of race exist in the literature, the construct of race must be examined. According to the Definitions of Race (2001), there are many definitions and origins of race. According to Merriam-Webster's Collegiate dictionary (2004), there are eight different definitions of race. One such definition reflects that a division of humankind possesses traits transmissible by descent and categorizes the possessor as distinctly human. Biological race can be defined as a phenotypically and/or geographically distinctive subspecific group, composed of people from a defined geographical or ecological region that possess characteristic phenotypic and gene frequencies distinguishable from other groups (King \& Stanfield, 1990). Because so many definitions of race exist, using common themes found in the definition of race, the author of this study will define race as a class or kind of people unified by geographical and ethnic origin.

During the second, or coping stage, the couple develops proactive and reactive strategies to handle a society unaccepting of interracial relationships. An unaccepting society may cause an 
interracial couple to insulate itself from potentially damaging or harmful situations and settings. In addition to insulation, the couple also becomes competent in negotiating destructive situations that may be unavoidable. As an interracial couple becomes proficient "in the process of insulation and negotiation, they begin to work together to establish sets of characteristic responses to a variety of situations" (Foeman \& Nance, 1999, p. 552). That is, an interracial couple should develop a repertoire of behaviors that can be easily engaged and are designed to avoid or defend from potentially harmful situations. For example, an interracial couple may join a support group or circumvent a racial issue by linking it to a bigoted source. Foeman and Nance also noted interracial couples learn how to avoid racially charged issues or language in public settings, which may be damaging to the relationship. The coping stage provides a channel in which the couple strengthens relational bonds by working through challenges faced by the couple. This stage determines whether a couple will survive or come apart by how they develop their own definitions of interracial couples and race (Foeman \& Nance, 1999).

Again, the stage of coping with social definitions of race may not be limited to couples involving Black and White people. Numerous types of interracial couples (e.g., White-Black, Hispanic-Black, or Asian-Hispanic) may face various social definitions of race. Despite these differences among interracial couples, interracial relationships as a whole could face societal pressures different from the societal pressures faced by same-race relationships. Similar to Black and White interracial relationships, other non-White individuals in interracial relationships also develop coping strategies to minimize the societal harm in which they may be exposed. Insulation and negotiation may be present in any interracial relationship, as it can be viewed as a survival tactic to protect the relational partners. Non-White participants are considered the minority when compared to Whites, so the generalizations provided by Foeman and Nance 
(1999) could be applicable to all non-Whites. Even when examining non-White interracial relationships, one partner may be considered the majority if placed in an environment where his/her race is of the dominant group. That is, the partner, regardless of race or ethnicity, should exhibit thoughts, feelings, or behaviors of the ingroup (Kaplan, 2002). The differences in cultural origin should not affect manifestations of ingroup or outgroup status. The stage of coping with social definitions should be applicable to people involved in any type of interracial relationship because of situations that involve awareness of group membership, insulation, negotiation, and dealing with societal and personal roles of race.

\section{Identity Emergence}

Foeman and Nance's (1999) third stage, identity emergence, is a process by which the members of an interracial couple redefines themselves by managing images of each other and their relationship. Like the model's second stage, interracial couples continue to develop and enact behaviors that are helpful to the continuation of the relationship. The behaviors present during the stage of identity emergence typically arise from coping with social definitions of race. Interracial couples are able to redefine and label their experience in a way, which challenges previously held norms (e.g., intraracial marriage, same-race children, similar family size, etc.), as well as taboos of society (e.g., interracial couples, interracial children, differing family traditions, differing religions, etc.). Because of the increasingly multicultural nature of the United States, interracial families may become more accepted in society (Foeman \& Nance). Until acceptance is the norm, identity emergence is an important part of sustaining an interracial relationship. With the increase in non-White U.S. residents and the number of interracial children climbing so quickly (Results of the 1996 Race and Ethnic Targeted Test), people may want to maintain their racial identity when entering an interracial relationship. Through the maintenance of racial 
identity, individuals in interracial relationships may identify the inclusion of a differing race in their lives as a source of strength and positivity (Foeman \& Nance), rather than a point of contention.

In order to maintain racial identity, one must constantly engage in identification with his/her racial culture. However, it is not uncommon for one to engage in disassociation with his/her racial culture. According to Hall (1976), identification can function "as an individual dynamism that is more or less unique of a particular person; and as a manifestation, and probably one of the chief manifestations of culture" (p. 204). The construct of disassociation is a vehicle which an individual can utilize to persist with actions involved with identification, but to a different culture “... so that self-respect can also be maintained” (Hall, 1976, p. 206). By disassociating the self from actions that could harm feelings of belonging, the person enacting disassociation behaviors believes he/she is in fact identifying with his/her own culture, despite the other's awareness of disassociation (Hall). In order for people in interracial relationships to view the interaction of two people as beneficial (e.g., cultural awareness, diversity, openness to new experience, collective experience dealing with race, etc.), each should identify with his/her own race while being aware of his/her partner's race identification.

\section{Maintenance}

The fourth stage of Foeman and Nance's (1999) model is maintenance. This stage is marked by an emergence of a couple's effective strategies and perspectives. Through the process of maintenance, interracial couples are able to revisit previous stages in response to any given need that arises. Although Foeman and Nance (2002) noted maintenance may result in revisiting different stages when raising interracial children, the concept of maintenance is present in every type of relationship (e.g., married, non-married, romantic, non-romantic, interracial, same-race). 
Over the past two decades, researchers have studied relational maintenance in a variety of contexts and relationships, including marital relationships, dating relationships, cross-sex nonromantic relationships, and same-sex relationships (Dainton, Zelley, \& Langan, 2003; Dindia \& Baxter, 1987; Haas \& Stafford, 1998; Hess, 2003; Stafford \& Canary, 1991; Messman, Canary, \& Hause, 2000; Vogl-Bauer, 2003). Stafford and Canary (1991) developed a relational maintenance typology gleaned from the examination of married, engaged, seriously dating, and dating couples. The researchers built on Ayres' (1983) and Dindia and Baxter's (1987) examination of strategies used in romantic relationships. Stafford and Canary's research efforts resulted in a typology consisting of the following relational maintenance strategies: (a) positivity, (b) openness, (c) assurances, (d) networks, and (e) sharing tasks. Canary, Stafford, Hause, and Wallace (1993) extended Stafford and Canary's (1991) typology by including the following five strategies: (a) joint activities, (b) cards/letter/calls, (c) avoidance, (d) antisocial behaviors, and (e) humor. To further explicate understanding of relationships, Dainton and Stafford (1993) examined the routine maintenance behaviors specific to romantic relationships. By highlighting the importance of routine relational maintenance behaviors in romantic relationships, the researchers augmented Stafford and Canary’s (1991) five-item typology by including the following strategies: (a) joint activities, (b) talk, (c) mediated communication, (d) avoidance, (e) antisocial behaviors, (f) affection, and (g) focus on self. Routine behaviors are "generally not performed with the express goal of maintaining the relationship, but, rather, for some other purpose" (Dainton \& Aylor, 2002, p. 53) The inclusion of routine behaviors in the study of relational maintenance provided a more comprehensive understanding of relational maintenance behaviors in romantic relationships. 
The first examination of the relational maintenance behaviors of minority relationships occurred in Haas and Stafford's (1998) study of gay and lesbian romantic relationships. The researchers examined the validity of commonly held assumptions of differences that exist between same-sex and opposite-sex romantic relationships. Using Dainton and Stafford's (1993) typology, Haas and Stafford determined same-sex partners used the same relational maintenance behaviors as opposite-sex partners. Same-sex partners, however, utilized the two additional strategies of gay/lesbian support environments and being the same as heterosexual couples (i.e., viewing their relationship similar to heterosexual relationships).

Researchers have examined various types of relationships, but most of the participants in studies have been White college students or people in those college students' social networks. Within these social networks, it logically follows that most participated in same-race relationships. Haas and Stafford's (1998) study of gay and lesbian relationships was the first to examine a minority group. Although the couple, compared to societal norms of sexuality, is considered a minority, an examination of the members within the couple highlights the similarity they have to one another (in their sexual orientation). This type of couple may parallel a samerace relationship in that the members of the couple can provide support for one another and be sensitive of each other's social place (e.g., their group membership, their social roles, and the role of sexuality in their relationship). However, an examination of the thoughts, feelings, and behaviors during the maintenance stage of interracial relationship development could shed light on the differences between partners in their group membership, social roles, cultural origins, and the role of race in the relationship. 


\section{Extension of Interracial Relationship Model}

Foeman and Nance's (1999) model of Black/White interracial relationship development provides an excellent theoretical backdrop for examining the dynamism of other interracial relationships. The model forwarded by Foeman and Nance appears to be a sound approach to examining and understanding the stages of interracial relationship development, but the model is purely conceptual. Research should focus on operationalizing the stages of this model to determine whether differences actually exist between each stage of interracial relationship development. Researchers have often utilized the tripartite of human action (i.e., cognition, affect, and behavior) to examine various contexts (e.g., Avtgis, West, \& Anderson, 1998; Bagozzi, 1982; and Lutz, 1977). According to Huitt (2006), cognition is the act or process of knowing through which knowledge is gained from perception or ideas. Affect is a feeling or emotion as distinguished from cognition, thought, or action (Huitt, 1999). According to Merriam-Webster's Collegiate dictionary (2004) behavior is an action performed by an organism involving action and response to stimulation. By determining the specific cognitive, affective, and behavioral processes people enact in interracial relationships, researchers can more fully understand the development of such relationships.

Additionally, Foeman and Nance (1999) presented this model based on differences between Black and White interracial relationships. The differences between Black and White relationships may mirror the differences between members of an interracial couple from different races. These differences may stem from the cultural origins of each race. Although there may be unique differences between various types of interracial relationships, the tensions that arise from those differences as stated in Foeman and Nance's model may be similar across interracial relationships. Because of the possible differences between interracial and same-race relationships 
in a myriad of factors including individual differences, group memberships, status differentials, and cultural origins, variations in relationship development should occur. When these characteristics are combined with the added stressors (e.g., societal pressures, racism, and stereotypes) unique to interracial couples, the relational developmental process could be fundamentally different from that of same-race couples. The end-result may be that the cognitive, affective, and behavioral characteristics in interracial relationships manifest themselves differently than those in same-race relationships. As such, utilizing the Foeman and Nance relational stages model, this exploratory study seeks to qualitatively examine the behaviors, thoughts, and feelings of people during the stages of interracial relationship development. More specifically, the following research questions are forwarded:

RQ1: Can Foeman and Nance's (1999) model of interracial relationship development be adapted into a generalizable interracial relationship development typology?

RQ2: Will there be a distinct difference in the affective, cognitive, and behavioral dimensions experienced in each stage? 


\section{CHAPTER TWO}

Method

This study employed a focus group methodology because it provides "a way to better understand how people feel or think about an issue..." (Krueger \& Casey, 2000, p. 4). The exploratory nature of this research justifies the use of focus groups. This type of methodology provides an environment conducive to the generation of multiple perspectives and unique information regarding the stages of interracial relationship development. Focus groups also provide a forum for discussing personal experiences relevant to those in interracial relationships. Previous research using this method has provided a typology of relational maintenance behaviors through inductive analysis (see Canary et al., 1993). Because of the conversational nature of focus groups, participants are able to critique as well as supplement one another's responses to open-ended questions through personal experiences. The conversational nature of these groups should then provide additional insights unable to be gleaned from closed-ended questions (Krueger \& Casey, 2000).

The focus group methodology also provides a useful manner of gathering information to better understand the thoughts and feelings of a group of people. Focus group interviews benefit exploratory research because of the self-disclosive nature of the process (Krueger \& Casey, 2000). Through the process of induction, focus group interviews provide researchers with an opportunity to understand the specific thoughts, feelings, and behaviors of a cohort and generalize those findings to a given population. The presence of a moderator also ensures that discussions stay on track through questioning, direction, and inclusion of all participants. For example, Avtgis et al. (1998) conducted focus groups to inductively determine the affect, cognition, and behaviors present in Knapp's (1978) stages of coming together and coming apart. 
The results of Avtgis et al.'s study indicated that the focus group methodology is effective in explicating the thoughts, feelings, and behaviors associated with relational typologies. As such, the application to interracial relationship development stages is warranted. In this study, focus groups were used to uncover the affect, the cognitions, and the behavioral dimensions present during the different stages of Foeman and Nance's (1999) interracial relationship development model. In comfortable and permissive settings, homogenous participants (i.e., participants with similar experiences) can provide information regarding what they have in common, in this case, interracial relationships (Krueger \& Casey, 2000).

\section{Participants and Procedures}

After receiving permission from the instructor, participants were recruited from communication classes at a large Mid-Atlantic university. Students were offered extra credit towards their final grade to participate in focus groups. Students who did not wish to participate were offered alternative opportunities to receive research credit (e.g. research paper or survey completion). Those who agreed to participate were informed about the nature of the study, the time of the meeting, and the meeting's location. Participants also provided with the researcher with contact information.

A single-category design (i.e., a design that examines differences between groups exhibiting the same characteristics) was used for four focus groups. The first focus group consisted of four women and six men, the second focus group consisted of four women and one man, the third focus group consisted of three women and two men, and the fourth focus group consisted of five women. Each focus group consisted of both men and women, all of which reported either being in an interracial relationship or having been in one at one time. Almost all participants reported currently being in an interracial relationship. 
Participants were informed about the purpose of the study and signed a consent form. All participants were notified that their responses would be kept confidential, their course standing would not be affected because of participation, and the sessions would be audiotaped. Participants were also informed of the nature of focus groups and were given a brief explanation of the four stages of interracial relationship development. All groups followed the same questioning route. The questioning route consisted of 15 questions identifying the thoughts, feelings, and behaviors during different relationship development stages (see Appendix A). Focus groups lasted approximately two hours. Once the focus group session concluded, the participants were thanked and dismissed.

Analysis of Data

After the interview data were gathered, participants' responses were examined. The principle researcher transcribed the audiotapes and analyzed responses to the key questions. Each line number was noted on the transcript and each group was distinguished through color-coding. All responses were divided into individual units and sorted by the question it answers (e.g., the behaviors exhibited during racial awareness or the feelings experienced during identity emergence). After initial sorting, the responses were then further divided on being characteristic of affect, cognition, or behavior. Once all relevant responses were categorized by question and response type, a descriptive summary of the focus group discussions was created. The descriptive summaries were then compared between groups to note similarities and differences. Comments were given different levels of importance based on the frequency, specificity, emotion (i.e., passion or enthusiasm attached to comment), and extensiveness (i.e., how many different people mention something) of the comment. The emotion and extensiveness of the responses were noted during focus group interviews. In addition to highlighting similarities and 
differences between the groups, a descriptive summary allowed continually reoccurring themes to be identified 


\section{CHAPTER THREE}

Results

The first research question asked whether Foeman and Nance's (1999) model of interracial relationship development could be adapted into a generalizable interracial relationship development typology. Long-table analysis of focus group transcripts yielded the following number of themes: (a) four themes for the stage of racial awareness, (b) five themes for the stage of coping with social definitions of race, (c) four themes for the stage of identity emergence, and (d) three themes for stage of maintenance. Table one reports the results. These themes are not mutually exclusive. All of the themes emerged in each of the four focus groups.

\section{Racial Awareness}

The four themes that emerged during the stage of racial awareness were perspective taking, social networks, interest in partner's differences, and attributing transgressions to partner's differences. For the purposes of this study, a transgression is defined as the violation of a relational contract. The perspective taking theme refers to an individual's attempt to understand the partner's perspective and racial place in society. Participants indicated that they tried to act appropriately when in the presence of the other partner's group. A representative response was "he's a lot more aware of cops than I am. He doesn't speed and is always looking around."

The social networks theme involves expressing interest by using different social networks. Participants spent more time with their partner's friends and family. Participants also indicated that regardless of the activities, they would interact with their partner's friends to appear interested and accepting of them. A representative response was "I stopped hanging out with my friends as much and started hanging out with all of his Asian friends." 
The interest in partner's differences theme refers to the showing of interest in activities, customs, or differences apparent in a partner (e.g., hair texture, skin color, customs). Participants noted they were attracted to someone who looked or sounded different. This attraction included showing excitement and eagerness when around the partner. A representative response was "I was attracted to the whole exotic thing."

The attributing transgressions to partner's differences theme was marked by giving more leeway to a partner after committing a misbehavior. Participants specified that they were less apt to reprimand, chastise, or inform their partner after the transgression took place than if they were of the same race. The lack of action was attributed to differences in culture or upbringing. A representative response was "You look past things that you normally wouldn't if it had been someone else." Coping with Social Definitions of Race

The five themes that emerged during the stage of coping with social definitions of race were ignoring, adapting behavior, avoidance, retaliation, and protection. The ignoring theme refers to people not addressing or recognizing negative comments, behaviors, or actions. Participants indicated that when confronted with a racially charged comment or situation, they would not acknowledge the issue or would change the subject. A representative response was "If someone said something to me or him about my race, one of us would just change the subject."

The adapting behavior theme involves behaving differently depending on the circumstances and environment of the interaction. Participants explained that they would behave in a more subtle manner in order to downplay any obvious differences. Subtle behavior could include changing word choice or speech style, dressing differently, or eliminating public displays of affection. A representative response was "I told my boyfriend that he had to wear khakis and a 
shirt that hit above his knees if he was going to come over for Christmas dinner. I didn't want my parents getting on us for me dating a 'gangsta."”

The avoidance theme concerns behaviors used to avoid situations that could be perceived as negative. Participants identified behaviors such as not spending time with specific family members or friends and removing themselves from an uncomfortable or dangerous situation. An uncomfortable or dangerous situation may be a circumstance where race is such a volatile issue that the tension may cause discomfort for the members of the couple or escalate to violence. A representative response was "We have to plan our vacations differently. We have to think about where we're going to be and what kind of people we are going to see."

The retaliation theme involves directly dealing with a negative event or circumstance. Participants reported that when another person behaves in a way that is perceived as negative, the member of the couple reacts directly to the instigator similarly or in a way that describes his/her feelings towards the behavior. For instance, if someone were to stare for too a long a period of time, someone may say, "What are you looking at?"

The protection theme concerns the actions taken to defend a partner depending on the circumstance or situation. Participants identified confronting a person who they perceived to be attacking their partner. Protecting the partner included warning someone who had made a harmful comment or justifying the relationship to a critical outgroup member. A representative response was "when my friends made a racist joke, I would call them out on it and tell them that that's not cool."

\section{Identity Emergence}

The four themes that emerged during identity emergence were togetherness, talk, involvement, and social support. The togetherness theme refers to the increased amount of time 
the couple spends alone and the behaviors enacted by the couple that establishes a sense of unity. Participants noted that they avoided other people who they thought could create a negative situation as well as reacted to situations similarly and in unison. A representative response was "We have an opportunity to learn more about each other because we are forced to see how we both react to the same situation. That makes us not only stronger, but it gives us a common enemy."

The talk theme involves the conversations that specifically concerns learning more about the other person. The partners used the new information and experiences to better identify with the other person. Participants acknowledged that more conversations took place because there was more to learn about the other person (e.g., culture, traditions, customs, perspectives). Additionally, they noted that they would disclose information explaining interests, experiences, and viewpoints to which their partner had not been exposed. A representative response was "We talked so much more than in any of my same-race relationships. We always talked about so many more things because I had never done a lot of the things he had done and he had never done a lot of the things that I have done."

The involvement theme refers to the new experiences that both partners experienced with each other. Participants indicated that they set out to try new experiences with which their partner was familiar with and vice versa. These experiences included, but are not limited to, trying new foods, visiting new places, interacting with people differently, and experiencing new holidays.

The social support theme is marked by the couple placing themselves in environments conducive to the health of their relationship. Participants identified that one of the most important things necessary for their own well-being and the well-being of their relationship was 
that of support from their family and friends. If family and friends were not supportive, people stopped associating with family and friends. In addition, participants would actively seek out other people who did approve of interracial relationships. A representative response was "I got a lot closer with his friends because they were a lot more accepting of our relationship than my friends."

\section{Maintenance}

The three themes that emerged during maintenance were efficiency of selection, awareness of differences, and awareness of the demographic nature of differences. The efficiency of selection theme was marked by an understanding of the strategies and behaviors deemed most effective and appropriate for the couple. Participants tended to revisit previous stages in Foeman and Nance's (1999) model and used those strategies that worked best for them. A representative response was “We avoided people or places we thought could be a problem. If we don't have to deal with it, then it doesn't become a fight or worry for us." Most participants identified avoidance, ignoring, and social support as the easiest and most effective strategies to use.

The awareness of differences theme is marked by an increase in understanding each partner's differences, strengths, and weaknesses. Participants indicated that they were slower to react negatively to a partner's transgressions than they would have earlier in the relationship. That is, the participant exhibited an increased threshold for negative affect when dealing with their partner's transgressions. This was attributed to the fact that they were already cognizant of their partner's typical reactions and perceptions. Participants also indicated that they approached potentially problematic or racially charged situations with more trepidation because of an awareness of how their partner could or would react. A representative response was 'We don't 
fight as much as before because we are more aware of where our differences are and what we don't see eye-to-eye on. Now, we just avoid the topic or accept that there are differences."

The awareness of the demographic nature of differences theme focuses on the realization that many of the differences present within a relationship are not due to race but a myriad of individual differences. Participants noted they did not think of themselves as involved interracially until someone outside of the relationship forced that upon them or a drastic difference presented itself (e.g., language, the way someone's hair grows, getting a sun burn). Most participants identified the term interracial relationship as a product of society. Participants also noted that the differences between people of different skin color mirrored that of the differences between height, weight, eye color, or hair color. A representative response was, "I don't think race is big deal to us who are in one [interracial relationship]. If it was, I wouldn't be dating someone who is 'different' than me. I think race isn't a big deal, but religion, geography, or socioeconomic status, that's more of a big deal."

The second research question asked if there would be a distinct difference among the affective, cognitive, and behavioral dimensions experienced in each stage. Long-table analysis of focus group transcripts revealed that the affective, cognitive, and behavioral dimensions were distinct from one another in each stage (see Table 2). Although the behavioral dimension differed across stages, the affective and cognitive dimensions exhibited no differences across stages. The behavioral dimension was congruent with the different strategies that were identified in response to Research Question One.

Although the affective dimension was distinct from the cognitive and behavioral dimensions, the affective dimension exhibited little variability across each stage of interracial relationship development. Affective responses included, but were not limited to, excitement, 
discomfort, indifference, feeling out of place, apprehension, hurt, and anger. A pervasive theme that emerged was that of anger or indifference when dealing with people who have a problem with interracial relationships. Further, participants exhibited feelings of uncomfortability, nervousness, and frustration when having to enact behaviors through all stages of interracial relationship development. Interestingly, participants noted a simultaneous sense of happiness, excitement, and pride in being able to share the experience with their partner, learning new things about their partner, and being generally unaware of racial differences. That is, the participants believed that the only reason race became a salient issue within their relationship was because people outside the relationship raised concerns regarding race. It should also be noted that couples in the maintenance stage attributed less negative affect stemming from the people within the relationship. People believed that the negative affect they experienced was a result of dealing with people outside the relationship who did not approve of interracial relationships and had nothing to do with them.

Similar to the affective dimension of each stage, although the cognitive dimension was distinct from the affective and behavioral dimensions, the cognitive dimension exhibited little variability across the stages of interracial relationship development. Cognitive responses included: (a) "I don't see color, I see another person," (b) “The whole interracial thing gets forced on you by other people," (c) "If those people who are close to you are accepting, it's a lot easier," (d) "We dealt with situations that people in a same-race relationship wouldn't have to deal with, and we learned a lot more about each other a lot faster because of it," and (e) "It's not like we always thought, 'hey, I'm in an interracial relationship.' We dealt with it when we had to, and we really only dealt with it when other people made us look at it." A few pervasive themes emerged in all focus groups and across most of the relational development stages. 
Participants often noted they did not think race was an issue during relationship development or across the life of the relationship. The interracial nature of the relationship became salient when the couple was forced to deal with a person or situation that did not approve of the interracial nature of the relationship. Participants also identified several benefits to being in an interracial relationship. These benefits included, but are not limited to, being exposed to new traditions, trying new foods, learning new languages, and becoming aware of new perspectives and ways of thinking. However, participants attributed the benefits of interracial relationships to culture, religion, family background, and geographical location instead of race. In addition, participants believed they bonded as a couple faster and more efficiently than in their same-race relationships because they were forced to deal with racially charged situations. This sentiment was exhibited by people who felt they put more emotional and behavioral effort into the relationship because of increased stress. The behavioral items which emerged matched the themes answering Research Question One. 


\section{CHAPTER FOUR}

Discussion

The purpose of this study was to determine whether Foeman and Nance's (1999) model of interracial relationship development could be adapted into a generalizable typology and whether there would be distinct differences in the affective, cognitive, and behavioral dimensions of each stage. The first research question concerned the adaptability of the model into a typology. The evidence of this study supports the adaptation of the model into a typology of interracial relationship development. People in interracial relationships engage in various behaviors during the development of their interracial relationship (i.e., perspective taking, sharing social networks, interest in partner's differences, attributing partner's transgressions to partner's differences, ignoring, adapting, avoiding, retaliating, protecting, togetherness, talk, involvement, social support, efficient use of strategies, awareness of difference, and awareness of the demographic nature of differences).

The findings of the present study provided initial support for Foeman and Nance's (1999) model of Black/White interracial relationship development. The results also suggested that this model may be applicable not only to the Black/White interracial relationship. Participants made it evident that an Asian/White interracial couple faced the same social situations that a Hispanic/Black or Black/White interracial couple would face. Thus, Foeman and Nance's model is not only applicable to the Black/White relationship but to the interracial relationships observed in each focus group.

The second research question asked whether there would be a distinction between the affective, cognitive, and behavioral dimensions within each stage of interracial relationship development. Interestingly, only the behavioral dimension differed across stages. Although the 
affective and cognitive dimensions were distinct from each other and the behavioral dimension, the affective and cognitive dimensions demonstrated little variability across stages. The only difference was during discussions of the maintenance stage, participants reported less negative emotions toward each other because of a heightened awareness of ingroup/outgroup differentiation than was reported in other stages. That is, couples attributed the emotions attached to the enactment of behavioral strategies to a reaction towards people outside the relationship forcing issues regarding racial differences. Couples did not believe the emotions attached to the behavioral strategies enacted stemmed from individual differences.

The findings pertaining to the behavioral dimension were not surprising given that people should behave differently during distinct stages of relational development. One would not enact the same behaviors when learning about his/her partner as he/she would when having to deal with a potentially harmful situation involving race. The findings pertaining to the affective and cognitive dimensions were noteworthy. More specifically, although the two dimensions were distinct from each other, the same themes appeared across all stages. This finding may be attributed to the association of an affect or cognition to a particular behavior and not to the developmental stage of the relationship. Although the affect and cognitions someone may experience in an interracial relationship may change over time, they may experience similar thoughts and feelings when enacting the behaviors indicative of each stage of interracial relationship development. An individual who is forced to see differences not previously considered and an individual who has to either avoid, ignore, or retaliate in racially charged situations may not behave similarly, but perhaps exhibit the same thoughts and feelings. Participants repeatedly differentiated between people who would consider being in an interracial relationship and those who would not. Those individuals who entertain the idea of being in an 
interracial relationship reported not thinking race was an issue and only contend with racially related situations when brought up by others (e.g., family members and friends). The interracial nature of the relationship was not an all-encompassing part of the relationship, but only a realization that was situation-specific.

It is important to distinguish whether the maintenance stage of the proposed typology of interracial relationship development differs from other relational maintenance typologies. Haas and Stafford (1998) examined the relational strategies of homosexual couples, another minority relationship, and found little differences between homosexual and heterosexual couples. Stafford, Dainton, and Haas (2000) examined the routine and strategic maintenance behaviors to develop an improved measure of relational maintenance behaviors while examining possible gender and sex differences as well as the relationships between maintenance behaviors and various relational characteristics (i.e., satisfaction, control mutuality, commitment, and liking). These findings raise concern as to whether the strategies within the maintenance stage of the proposed typology of interracial relationship development differs from other relational maintenance typologies, if the typology is truly unique to interracial relationships, or if the typology is applicable to the development of any minority relationship.

The Stafford et al. (2000) typology of relational maintenance behaviors includes (a) assurances (assuring the partner of the relationship's future), (b) openness (discussing feelings), (c) conflict management (addressing and understanding conflict), (d) shared tasks (jointly performing tasks), (e) positivity (communicating positive messages), (f) advice (giving counsel), and (g) social networks (spending time with mutual friends). The Haas and Stafford (1998) typology of gay/lesbian relational maintenance behaviors (a) positivity, (b) openness, (c) assurances, (d) sharing tasks, (e) cards/letters/calls, (f) social networks, (g) supportive 
environments, and (h) being the same as heterosexual couples. It is evident that there are small similarities between certain stages of the proposed typology for interracial relationship development and of both Stafford et al.'s and Haas and Stafford's typologies of relational maintenance behaviors. All three typologies mention the use of sharing tasks, and two of the three typologies note the use of social networks and supportive environments. Haas and Stafford found the strategies used by gay and lesbian couples were very similar to the strategies used by heterosexual couples with the exception of two additional strategies (i.e., social support and being the same as heterosexual couples). Although three of the behaviors in the typology of interracial relationship development surfaced in the two other typologies, it seems evident that the stage of maintenance in the proposed typology of interracial relationship development is distinct from other relational maintenance typologies (Canary et al., 1993; Dainton \& Stafford, 1993; Dainton, Stafford, \& Canary, 1994; Dindia \& Baxter, 1987; Haas \& Stafford, 1998; Stafford et al., 2000; Stafford \& Canary, 1991).

Another concern is whether the proposed typology is truly unique to interracial relationships. According to Foeman and Nance (1999), couples in the stage of racial awareness should become aware of how race plays a role in the development of the relationship, how the attraction to someone different may be scrutinized socially, and how a member of the couple should become aware of his/her partner's role in society regarding race. The behaviors that emerged during this stage were perspective taking, using social networks, becoming interested in partner's differences, and attributing transgressions to partner's differences.

Perspective taking behavior may appear to be a more salient issue for people in interracial relationships, but repeatedly, participants felt that perspective taking was a part of every relationship. Certain issues were more relevant when dealing with race (e.g., awareness of police 
presence, discrimination, racism) but the majority of the responses were indicative of learning and empathizing towards the other relational partner. The use of social networks was a behavior people used to become closer to the other partner's friends. Periodically, people noted that this behavior was not limited to interracial couples but rather a tactic used to show interest in the other person and establish common ties. The interest in partner's differences emerged as a product of increased individual differences. One comment that highlighted this point was "I was excited to be dating someone who was so different than me... not just race though; he sounded different, acted different. I mean, he could probably have passed for someone with a really good tan if he didn't open his mouth." Attributing transgressions to a partner's differences was perhaps the behavior most affected by race during this stage. Continually, many of the participants mentioned that various relational transgressions were grounded in racial differences between participants. Thus, social desirability, or the tendency to behave in a way we believe is socially acceptable and desirable, would prompt them to either stay in the relationship or overlook certain transgressions because of the interracial nature of the relationship. A person who leaves their partner because of an action that may be attributed to race (e.g., being boisterous in public, making a sexist remark, different table manners) may be viewed with negative affect in society.

The following behaviors emerged during the stage of coping with social definitions of race: ignoring, adapting behavior, avoiding, retaliating, and protecting. It is important to note that this stage may not be applicable to interracial relationships. However, the behaviors enacted during the stage of coping with social definitions of race appeared to be situation-specific and salient to interracial relationships. Although the examples presented by all participants pertained to race (e.g., negative comments, looks, positively and negatively valenced questions, positively 
and negatively valenced behaviors), the thoughts and feelings surrounding those behaviors may be experienced by anyone dealing with the same situations stemming from a different issue. One does not have to be in an interracial relationship to cite the same type of circumstances that the participants in the study presented. An individual who is in a romantic relationship with someone from a different religion, socioeconomic background, or location may easily experience a negatively perceived situation with any of these characteristics. Thus, that individual may enact different behaviors but go through the same stage of coping with social definitions of religion, socioeconomic status, or geography as someone in an interracial relationship when under social scrutiny.

The following behaviors emerged during the stage of identity emergence: togetherness, talk, involvement, and social support. Like the previous stages of racial awareness and coping with social definitions of race, although the behaviors enacted during identity emergence may be unique to interracial relationships, the stage of identity emergence may not be limited to interracial relationships. The behaviors during this stage were indicative of doing more things alone, talking more to identify with the other partner, trying new things, and surrounding oneself with supportive people. It could be argued that the more differences that exist between members of the couple, the more behaviors regarding identity emergence would be enacted. Therefore, relationships with members who believe themselves to be different with regards to other characteristics (e.g., height, weight, dress, language) would exhibit the same behaviors as those people who believed themselves to be different in interracial relationships.

The behaviors that emerged in the final stage of maintenance included efficiency of selection, awareness of differences, and awareness of the demographic nature of differences. Again, these behaviors are believed to be indicative of interracial relationships but the stage of 
maintenance may be indicative of any romantic relationship that has to contend with differences that may be socially scrutinized. All participants noted they developed a repertoire of strategies and behaviors that worked most efficiently, effectively, and appropriately for themselves and their partner. Although it seems logical to believe any couple type should enact the most efficient behaviors, the efficiency of the selection of behaviors emerged as a distinct strategy in the stage of maintenance. The awareness of differences emerged as a product of people understanding the limitations and boundaries of their partner and their relationship. People also expressed listening and empathizing more. Participants disclosed that this behavior was not based on race, but rather on a concern for the other person and the well being of the relationship. Realization of the source of interracial differences was marked by the interracial couples realizing that although outgroup members perceived the relationship as different because of race, couple members saw race as another individual difference. Most participants emphasized they were not concerned about race unless someone outside the relationship raised the issue of race. A comment indicative of this was "There is stress in interracial relationships that you deal with just like in any relationship, I just think that issues come up because her family might not like me, or I don't know her friends, or we may have different goals, not that I'm darker than she is."

The interracial relationship provided the best medium for which to study the manifestation of behaviors for each stage of relationship development. Interracial couples may be the couple type that contends with the most socially stigmatized individual difference. However, it is because of individual differences that the proposed typology of interracial relationship development may not be limited to interracial relationships. The individual behaviors within each stage may be unique to interracial relationships, but the stages of relationship development may be applicable to other relationships. Although the interracial 
nature of a relationship and the presence of different skin colors could be the most obvious differences to someone outside the relationship, other differences may exist. Two White individuals living on opposite ends of the country may have more differences to contend with than a Hispanic and an Asian individual who grew up in the same city. Any two people who are vastly different from each other (e.g., dress, language, style, height, social networks, religion) may deal with the same issues that present themselves in interracial relationship development. It may be possible that race is another demographic variable that may contribute to the overall amount of effort that couple members must put into the relationship for the relationship to continue.

Although the model forwarded by Foeman and Nance (1999) appeared parsimonious in this study, it may not have been valid. The insufficiency of the model may be evident in the model's lack of overall support. The findings initially supported the model because of the operationalization of each stage of interracial relationship development. Participants may have attempted to frame their answers to the key questions to fit within each stage of the model. A further examination of the findings indicated a possible difference between the applicability of the stages of the model and the strategies indicative of each stage. The results indicated that the individual stages of the proposed typology (as well as Foeman and Nance's model) may not be unique to interracial relationships. However, the specific strategies and behaviors within each stage of the proposed typology may be unique to interracial relationships.

\section{Limitations}

There are limitations to this study. First, there appeared to be a representative amount of minorities but a large proportion of the participants were White. Although many of the participants spoke on behalf of their partner, it is hard to believe participants were aware of the 
affect and cognitions experienced by their partners. Second, more women than men participated in this study. A more representative sample of men would have been beneficial. It should be noted, however, that the men who did participate contributed as much as women to the questions during focus groups. Third, a large university campus may be more liberal than the majority of the country. This limitation may have been circumvented because participants came from a variety of locations to attend school (e.g., Africa, Puerto Rico, New York, New Jersey, West Virginia, and Florida). Fourth, the lack of anonymity during focus group interviews may have affected the results. Although participants were guaranteed anonymity, several remained fixated on the tape recorder during the focus group interviews. This fixation may have limited the amount of information they were willing to disclose. Because of the lack of anonymity, participants may have also been subject to a social desirability bias. Participants were very willing to discount the awareness of race within the relationship. This finding may be attributed to participants not wanting to disclose that race is a salient issue. It is possible that people in interracial relationships are more cognizant of race and the interracial nature of their relationship than they revealed. Additionally, membership within participants may have affected responses. Because of the large number of White participants, minority couple members may have been hesitant to disclose information in an environment they perceived to be unsupportive. Fifth, participants were recruited at a large Mid-Atlantic university. Although participants came from varied backgrounds, interracial relationships may be more acceptable among college students. There is reason to believe that the acceptability of interracial relationships among college students may not have been an issue because of the inclusion of married and engaged people, people from various ethnic backgrounds, and people from various geographical origins.

\section{Future Directions}


Future research should consider further exploring interracial relationship development. There is a possibility that the stages within the proposed typology of interracial relationship development may be applicable to the development of any relationship in general. The model forwarded by Foeman and Nance (1999) may not be unique to interracial relationships, but the strategies within each stage of the proposed typology were found to be unique to the interracial relationships observed. These findings may have implications to the study of relational maintenance by providing a better understanding of how relationships develop. Constructing a scale that would measure the frequency of behaviors and the presence of certain emotions and thoughts could enable quantitative researchers to correlate the thoughts, feelings, and behaviors of relational development to other interpersonal communication constructs. This study offers a preliminary empirical investigation into the development interracial relationships. Furthermore, the present study examines the affective, cognitive, and behavioral dimensions of each stage and future research should further examine whether the examples found in each dimension are unique to interracial relationships or if the stages of interracial relationship development can be generalized across various relationship types. 


\section{References}

Avtgis, T. A., West, D. V., \& Anderson, T. L. (1998). Relationship stages: An inductive analysis identifying cognitive, affective, and behavior dimensions of Knapp's Relational Stages Model. Communication Research Reports, 15, 280-287.

Bagozzi, P. R. (1982). A field investigation of causal relations among cognitions, affect, intentions, and behavior. Journal of Marketing Research, 19, 562-583.

Baldwin, J. R., Day, L. E., \& Hecht, M. L. (2000). The structure(s) of racial attitudes among White college students. International Journal of Intercultural Relations, 24, 553-577.

Canary, D. J., Stafford, L., Hause, K. S., \& Wallace, L. A. (1993). An inductive analysis of relational maintenance strategies: Comparisons among lovers, relatives, friends and others. Communication Research Reports, 10, 5-14.

Dainton, M., \& Stafford, L. (1993). Routine maintenance behaviors: A comparison of relationship type, partner similarity and sex differences. Journal of Social and Personal Relationships, 10, 255-271.

Dainton, M., Stafford, L., \& Canary, D. J. (1994). Maintenance strategies and physical affection as predictors of love, liking, and satisfaction in marriage. Communication Reports, 7, 8898.

Dainton, M., Zelley, E., \& Langan, E. (2003). Maintaining friendships throughout the lifespan. In D. J. Canary \& M. Dainton (Eds.), Maintaining relationships through communication: Relational, contextual, and cultural variations (pp. 79-102). Mahwah, NJ: Erlbaum.

Definitions of Race (2001). Retrieved January 12, 2006, from the Center for the Study of White American Culture: A Multiracial Organization Web site: http://www.euroamerican.org/ library/definitions race.asp. 
DeWine, S., \& Daniels, T. (1992). Beyond the snapshot: Setting a research agenda in organizational communication. Communication Yearbook, 16, 331-346.

Dindia, K., \& Baxter, L. A. (1987). Strategies for maintaining and repairing marital relationships. Journal of Social and Personal Relationships, 4, 143-158.

Foeman, A. K., \& Nance, T. (1999). From miscegenation to multiculturalism: Perceptions and stages of interracial relationship development. Journal of Black Studies, 29, 540-557.

Foeman, A. K., \& Nance, T. (2002). Building new cultures, reframing old images: Success strategies of interracial couples. The Howard Journal of Communications, 13, 237-249.

Greene, R. R., Watkins, M., McNutt, J., \& Lopez, L. (1998). Diversity defined. In R. R. Greene \& M. Watkins (Eds.), Serving diverse constituencies (pp. 29-57). New York: Aldine de Gruyter.

Haas, S. M., \& Stafford, L. (1998). An initial examination of maintenance behaviors in gay and lesbian relationships. Journal of Social and Personal Relationships, 15, 846-855.

Hall, E. T. (1976). Beyond culture. Garden City, NY: Doubleday.

Harris, T. M., \& Kalbfleisch, P. J. (2000). Interracial dating: The implications of race for initiating a romantic relationship. The Howard Journal of Communications, 11, 49-64.

Hecht, M. L. (1978a). The conceptualization and measurement of interpersonal communication satisfaction. Human Communication Research, 4, 253-264.

Hecht, M. L. (1978b). Toward a conceptualization of communication satisfaction. Quarterly Journal of Speech, 64, 47-62.

Hess, J. A. (2003). Maintaining undesired relationships. In D. J. Canary \& M. Dainton (Eds.), Maintaining relationships through communication: Relational, contextual, and cultural variations (pp. 103-124). Mahwah, NJ: Erlbaum. 
Hofstede, G. (1984). The cultural relativity of the quality of life concept. Academy of Management Review, 9, 389-398.

Houston, M., \& Wood, J. T. (1996). Difficult dialogues, expanded horizons: Communicating across race and class. In J. T. Wood (Eds.), Gendered relationships (pp. 39-56). Mountain View, CA: Mayfield.

Huitt, W. (1999). The affective system. Educational Psychology Interactive. Valdosta, GA: Valdosta State University. Retrieved May 8, 2006, from http://chiron.valdosta.edu/ whuitt/col/affsys/affsys.html.

Huitt, W. (2006). The cognitive system. Educational Psychology Interactive. Valdosta, GA: Valdosta State University. Retrieved May 8, 2006, from http://chiron.valdosta.edu/ whuitt/col/cogsys/cogsys.html.

Interracial Married Couples: 1960 to Present (1999). Retrieved November 18, 2005, from U.S. Census Bureau Web site: http://www.census.gov/population/socdemo/ms-la/tabms-3.txt.

Kaplan, A. M. (2002). Factors predicting Whites' involvement in interracial relationships. Dissertation Abstracts International, 65, 12B.

King, R. C., \& Stansfield, W. D. (1990). A dictionary of genetics. New York: Oxford University Press.

Knapp, M. L. (1978). Social intercourse: From greeting to goodbye. Needham Heights, MA: Allyn \& Bacon.

Krueger, R. A., \& Casey, M. A. (2000). Focus groups: A practical guide for applied research $\left(3^{\text {rd }}\right.$ ed.). Thousand Oaks, CA: Sage.

Lutz, R. J. (1977). An experimental investigation of causal relations among cognitions, affect, and behavioral intention. Journal of Consumer Research, 3, 197-208. 
Martin, M. M., \& Anderson, C. M. (1995). Roommate similarity: Are roommates who are similar in their communication traits more satisfied? Communication Research Reports, $12,46-52$.

Martin, J. N., Hecht, M. L., \& Larkey, L. K. (1994). Conversational improvement strategies for interethnic communication: African American and European American perspectives. Communication Monographs, 61, 236-255.

McCroskey, J. C., Richmond, V. P., \& Daly, J. A. (1975). The development of a measure of perceived homophily in interpersonal communication. Human Communication Research, 1, 323-332.

Merriam-Webster's Collegiate Dictionary, (2004). Retrieved January 12, 2006, from MerriamWebster Collegiate Web site: http://www.merriam-webstercollegiate.com.

Messman, S. J., Canary, D. J., \& Hause, K. S. (2000). Motives to remain platonic, equity, and the use of maintenance strategies in opposite-sex friendships. Journal of Social and Personal Relationships, 17, 67-94.

Mills, J. K., Daly, J., Longmore, A., \& Kilbride, G. (1995). A note on family acceptance involving interracial friendships and romantic relationships. The Journal of Psychology, $129,349-351$.

Molicia, K. A., Gray, B., \& Trevino, L., K. (2003). Racial homophily and its persistence in newcomers' social networks. Organization Science, 14, 123-136.

Profile of General Demographic Characteristics (2000). Retrieved December 21, 2005, from U.S. Census Bureau Web site: http://www.census.gov/prod/cen2000/doc/ProfilesTD.pdf. Race of Wife by Race of Husband (1998). Retrieved November 17, 2005, from U.S. Census Bureau Web site: http://www.census.gov/population/socdemo/race/interractab1.txt. 
Results of the 1996 Race and Ethnic Targeted Test (2001). Retrieved November 17, 2005, from U.S. Census Bureau Web site: http://www.census.gov/population/www/documentation/ twps0018/section-1.html.

Rogers, E. M., \& Bhowmik, D. K. (1970). Homophily-heterophily: Relational concepts for communication research. Public Opinion Quarterly, 34, 523-538.

Stafford, L. \& Canary, D. J. (1991). Maintenance strategies and romantic relationship type, gender and relational characteristics. Journal of Social and Personal Relationships, 8, 217-242.

Stafford, L., Dainton, M., \& Haas, S. (2000). Measuring routine and strategic relational maintenance: Scale revision, sex versus gender roles, and the prediction of relational characteristics. Communication Monographs, 67, 306-323.

Vogl-Bauer, S. (2003). Maintaining family relationships. In D. J. Canary \& M. Dainton (Eds.), Maintaining relationships through communication: Relational, contextual, and cultural variations (pp. 31-49). Mahwah, NJ: Erlbaum.

Vonk, M. E. (2001). Cultural competence for transracial adoptive parents. National Association of Social Workers, 46, 246-255.

Watts, R. E., \& Henriksen, R. C., Jr. (1998). The interracial couple questionnaire. The Journal of Individual Psychology, 54, 368-374.

Yancey, G., \& Yancey, S. (1998). Interracial dating: Evidence from personal advertisements. Journal of Family Issues, 19, 334-348.

Yancey, G. (2002). Who interracially dates: An examination of the characteristics of those who have interracially dated. Journal of Comparative Family Studies, 33, 179-190. 


\title{
Appendix A
}

\author{
Script for Focus Groups
}

\section{Opening}

Thank you for coming and taking time for today's focus group. My name is Juan D'Brot and I am a Master student here at the WVU Comm Department. Feel free to get some refreshments before we start (note: I will provide refreshments before the beginning of each focus group).

First, I want to explain what a focus group is, why we are doing this focus group and what we hope to learn. A focus group is a controlled, planned discussion that gathers detailed information about a certain topic. I am interested in learning more about the experiences people go through in interracial relationships. With the information I gather, I hope to improve people's understanding about interracial relationships and their development.

Today's focus group is one of several that I will be conducting. Your comments will be audio taped so I ask that you please speak one at a time. I want to assure you that what you say is for my information-gathering purposes only. Your name will NOT be attached to your comments. I also ask that you protect each other's privacy and not discuss today's discussion with others.

In our discussion, we'll be talking about specific stages that couples in interracial relationships go through (note: at this point, I will hand out a sheet with the definitions of the four stages of interracial relationship development). The sheet in front of you explains these four stages.

The first stage, racial awareness, is when you become familiar with the similarities and differences between you and your partner. You realize that you are attracted to a person of a different race. You also realize that your partner belongs to different groups than you do. These group differences may be based on racial, religious, political, or economic differences. You also become sensitive of how your and their racial groups are treated in society.

The second stage, coping with social definitions of race, is when you learn how to react to other people's assumptions, thoughts, or behaviors when they look at you as an interracial couple. These reactions can lead you to avoid certain situations or people. Your relationship grows as a result of working through challenges and talking about experiences that are racially charged.

The third stage, identity emergence, is when you define your relationship as different from samerace relationships. The members of the relationship see dating interracially as a source of positive, instead of negative things. At this stage, you either embrace your own race, your partner's race, or embrace the interracial nature of your relationship.

The fourth stage, maintenance, is when you know what effective behaviors help keep your relationship going. There is a realization that you have done all these things in the past, both easy and hard, that have helped your relationship remain stable and strong. You realize that you can revisit previous stages in order to address any experiences that may come up. 


\section{Appendix A (continued)}

These are the four stages we will be using when talking about interracial relationships. Feel free to look at your handout if you need to remember what each stage deals with. Are there any questions before we begin? (note: I will answer any questions from participants).

Questioning Route

\section{Opening question}

1.) To begin the discussion, let's go around the table, introduce yourself, tell us your race, the race of your significant other, and how long you've been in an interracial relationship (Continue until all have participated).

\section{Transition Question}

2.) What kinds of experiences have you had when you are with your partner dealing with race? Some negative examples might be overhearing comments in a restaurant, getting a strange look in a bar, not being greeted when you enter a store, or not being accepted by your parents. Some positive examples might be being exposed to new foods, learning about a new culture, or being embraced by your partner's family.

\section{Key Questions}

\section{Stage 1 - Racial Awareness}

3.) Please refer to your handout. Racial awareness is when you realize that you and your partners belong to different races and different groups. What did you do when you realized you were attracted to a person of another race?

4.) What did you feel when you realized your relationship was unique from that of same-race relationships.

5.) What did you think when you realized you and your partner were from different races?

Stage 2 - Coping with Social Definitions of Race

6.) Please refer to your handout. Coping with social definitions of race is when you learn how to react to others judgments about your relationship and learn what behaviors work

for you as a couple. What did you do to deal with other people's view of interracial relationships?

7.) What kind of feelings did you experience when you and your partner dealt with situations involving race? For instance, standing out in a crowd because of appearances or being asked questions about interracial relationships. 


\section{Appendix A (continued)}

8.) Did you and your partner ever experience a racially charged situation? What were you thinking? For example, what did you think when you've had to deal with someone who doesn't approve of interracial relationships or deal with someone who is interested about your relationship because of racial differences?

\section{Break}

At this time, we are going to take a break. Let's start back up again in about five minutes.

Stage 3 - Identity Emergence

9.) Please refer to your handout. Identity emergence is when you start to look at your relationship as unique from same-race relationships. Did you do anything different in your interracial relationship that showed it was unique when compared to any previous same-race relationships you may have had?

10.) What kind of feelings did you experience when comparing your relationship to same-race relationships you've had in the past?

11.) What kind of benefits do you think there are to being in an interracial relationship?

Stage 4 - Maintenance

12.) Please refer to your handout. Maintenance is when you use effective behaviors to keep your relationship going. What do you do to maintain your relationship?

13.) What do you think about when you maintain your relationship?

14.) What do you feel when maintaining an interracial relationship?

\section{Ending}

15.) I wanted you to help me understand what people think, feel, and do during these different stages of interracial relationship development. Is there anything I missed? Is there anything you want to say that you didn't have a chance to?

\section{Conclusion}

I wanted to thank you for your time, effort, and participation during this focus group. Everything that you told me was very helpful and beneficial. Your responses will be used to develop a better understanding of how interracial relationships develop and function. Again, thank you for your time and for everything we have discussed today. Should you have any questions or concerns, or if any questions or concerns arise in the future, do not hesitate to call my advisor or me at (304) 293-3905. 
Table 1

Typology of Interracial Relationship Development
Strategy
Example

\section{Racial Awareness}

Perspective Taking

"I tried to see where he was coming from, what kind of stuff that he had to deal with that I didn't."

"I learned how to act with her family and she learned how to act with mine."

Social Networks

"I hung out with his friends more, even though they did things that I wasn't interested in."

"We made an effort to include each other in almost everything we did with our own families."

Interest in Partner's Differences

"I was excited to be dating someone who was so different than me."

"I was attracted to the whole exotic thing."

Attributing Transgressions

"I made concessions about his behavior, maybe to Partner's Differences because that's his culture."

"I just figured he had a different way of thinking, you know, a different perspective."

\section{Coping with}

Social Definitions of Race

Ignoring

"I try not to pay attention to what other people say."

"If someone makes a racial comment, we would just walk away." 
Table 1 (continued)

Strategy

Adapting Behavior

Avoidance

Retaliation

Protection

\section{Example}

"We would try to downplay the differences if we were with people who weren't approving or situations that either one of us weren't comfortable in."

"We stopped the whole PDA thing when we were around the elderly or people who we thought would try and make us feel uncomfortable about our relationship."

"My family has a problem with it, so we don't go anywhere near them."

"We didn't feel safe at the bar, it was just the two of us and like six of them who were bothering us, so we left."

"If someone's going to stare at me, then I'm going to stare right back."

"I confronted this woman who just turned her head all the way around and said, 'That's disgusting."'

"I had to defend my boyfriend to my grandmother when she said I shouldn't be dating that dark skinned boy."

"When my family would speak in a different language so she couldn't understand, I would make them stop and explain what they were saying."

\section{Identity Emergence}

Togetherness

"We started doing more things alone, trying to avoid other people, cause you never know who can cause you problems." 
Table 1 (continued)

Strategy

Talk

Involvement

Social Support
Example

"We had to defend and justify our relationship together and that made us a lot stronger for it in the end, faster than in any of my other relationships."

"We talked more in our relationship than I ever had in a same-race relationship. There was just so much more to learn about each other and his culture."

"We tried to share interests, so I would tell him what interested me that I thought he never did, and he told me what he liked that he thought I had never done."

"I tried new foods, tried to learn her language, and experienced new traditions."

"We both tried new things that we did that the other had never done before."

"We tried to surround ourselves with people who didn't have a problem with it, being interracial I mean."

"I got a lot closer with his friends cause they were a lot more accepting of our relationship than my friends."

\section{Maintenance}

Efficiency of Selection

"It got easier as our relationship went on. We knew what worked for us and what didn't in terms of dealing with other people."

"We learned that we couldn't just ignore everyone all the time, so we just don't visit my family anymore. It becomes avoidance now instead." 
Table 1 (continued)

Strategy

Awareness of Differences

Awareness of the Demographic Nature of Differences
Example

"We don't attack each other because we know that we come from different families and backgrounds. We realize now how our differences affect our decisions and how we react to certain people, situations, or things."

"We listen to each other more now. I know he has a different perspective than I do and vice versa."

"I feel like its outside elements that makes an interracial relationship what it is. If it were just about the relationship itself, there would be no interracial term, it's a society thing."

"There are some internal differences, but the difference between skin color is the same difference between eye color and height. If I dated someone who was four feet tall, I'd probably deal with the same problems that if I dated a Hispanic girl." 
Table 2

Affective, Cognitive, and Behavioral Dimensions of Each Stage

Dimension Example

\section{Racial Awareness}

Affective

Excitement, Interest, Discomfort, Indifference, Out of Place, Strange, Nervousness, Apprehension, Anger.

Cognitive

"I don't see color, I see another person."

"You can't change what other people think, but all they see is skin color, we don't."

"I'm attracted to girls of all races."

"I didn't see any differences until he was talking to his mom in a different language."

"The whole interracial thing gets forced on you by other people."

Behavioral

Taking partner's perspective.

Sharing and using partner's social networks.

Becoming interested in partner's differences.

Attributing partner's transgressions to their differences

\section{Coping with Social Definitions of Race}

Affective Annoyance, Anger, Loss of Control, Indifference, Out of Place, Nervousness, Uncomfortable, Hurt, Uneasiness, Enjoyment, Pride.

Cognitive

"I was raised not to see color, others see it that aren't in the relationship."

"You can't change what other people think, but through more exposure, less people will have problems with it. " 
Table 2 (continued)

Dimension Example

"Same race relationships are easier cause you don't have to deal with people who don't agree with interracial relationships."

"It's harder when the people who are close to you aren't approving."

“The differences aren't cause you're different races, but because the backgrounds are different. Other people only see the race thing though, it's color they see."

"The appearance is just another difference, just like race, background, family history, whatever."

Behavioral

Ignoring negative comments

Adapting behavior to the environment.

Avoiding potentially harmful or negative situations.

Retaliating during a negative situation towards the instigator.

Protecting the other partner.

\section{Identity Emergence}

Affective

Hurt, Faith in Partner, Pride, Anger, Sadness, Happiness, Nervousness, Apprehension, Indifference.

Cognitive

"I experienced a bit of culture shock when trying to get to know her family."

"I don't find any differences between my interracial relationship and previous same-race relationships when we're alone."

"Misinterpretations are a negative thing in any relationship."

(table continues) 
Table 2 (continued)

Dimension

Example

"We are stronger than same-race relationships because we have to go through more."

"The newness wears off like in any relationship."

"I may have been more sympathetic and stayed in the relationship longer than I should have cause it's interracial, not backing out."

Behavioral Doing more things together and avoiding others.

Talking more about new experiences and the relationship.

Becoming more involved in each other's families, culture, and traditions.

Surrounding oneself with people who are supportive of your relationship.

\section{Maintenance}

Affective

Cognitive

Behavioral
Anger, Disgust, Frustration, Pride, Indifference.

"Race is just another individual difference."

"I didn't think race was a big deal. It may be a big deal to other people, but it isn't to us."

"The hard part of being in an interracial relationship is not because we are interracial, but because we have differences like any other relationship."

"People shouldn't care about race because it's not a big deal."

"It's how you dress, how you talk, how you look, not what color your skin is or what race you are."

Using the most efficient and appropriate strategy for the relationship. 
(table continues)

Table 2 (continued)

Dimension

Example

Becoming aware of what differences we do have and how those differences affect our behavior and interactions.

Identifying the source of the differences and what those differences actually represent. 
Curriculum Vitae

Juan M. D'Brot

Home:

1316 Virginia St. E.

Apt. 308

Charleston, WV 25301

(304) 319-0479

jmdbrot@hotmail.com
Work:

Edvantia

P.O. Box 1348

Charleston, WV 25325

(800) 624-9120

juan.dbrot@edvantia.org

\section{Education}

\begin{tabular}{|c|c|c|}
\hline Master of Arts & West Virginia University & $\begin{array}{l}\text { Expected: } \\
\text { August, } 2006\end{array}$ \\
\hline Major: Communication Studies & Concentration: Theory and Research & GPA:3.92/4.00 \\
\hline & West Virginia University & May, 2005 \\
\hline Major: Communication Studies & Concentration: Data Analysis & GPA: $3.39 / 4.00$ \\
\hline
\end{tabular}

\section{Academic Interests}

Research Methods, Organizational Communication, Interpersonal Communication

\section{Professional Convention Research Presentations}

Goodboy, A. K., D’Brot, J. M., IV, Baker, K. S. (2006, April). Paper presented at the annual meeting of the Eastern Communication Association, Philadelphia, PA.

\section{Research in Progress}

Dunleavy, K., Chory-Assad, R. M., D’Brot, J. M., IV, Meehl, S., Glover, N. (2006). Deception in the organization: Distorting, withholding, and honest messages.

Weber, K., D'Brot, J. M., IV, \& Hixson, N. K. (2006). Federally funded research in association with the Center for Organ Recovery and Education.

\section{Completed Research Projects}

D’Brot, J. M., IV. (2004). Do women actually study more than men?

D’Brot, J. M., IV. (2004). Correlation of perception of illegal drug use and academics.

(Thesis) D'Brot, J. M., IV. (2006). The development of a typology for interracial relationships. 
D'Brot, J. M., IV. (2005). The relationship between student's perceptions of teacher selfdisclosure, homophily, and credibility.

D'Brot, J. M., IV, \& Hixson, N. K. (2006). Conflict in marriage: Relationships with argumentativeness, verbal aggressiveness, self-disclosure, and marital quality.

Goodboy, A. K., D’Brot, J. M., IV, Baker, K. S. (2006, April). Paper presented at the annual meeting of the Eastern Communication Association, Philadelphia, PA.

Teaching Experience

\section{Guest Instructor}

West Virginia University, Morgantown, WV (2005 - 2006)

Comm 105 - Introduction to Mass Media (Fall 2005)

Comm 105 - Introduction to Mass Media (Spring 2006)

\section{Course Assistant}

West Virginia University, Morgantown, WV (2005 - 2006)

Comm 105 - Introduction to Mass Media (Fall 2005)

Comm 105 - Introduction to Mass Media (Spring 2006)

\section{Honors}

Inducted into Lambda Pi Eta Communication Honors Fraternity (2005)

\section{Computer Knowledge}

\section{SAS}

SPSS

LISREL

Microsoft Office Products (Word, Excel, PowerPoint, and Access)

Professional Memberships

Eastern Communication Association (ECA)

Lambda Pi Eta 